\title{
Fabrication of Eco-Friendly Betanin Hybrid Materials Based on Palygorskite and Halloysite
}

\author{
Shue $\mathrm{Li}^{1,2,3}$, Bin $\mathrm{Mu}^{1,3, *}$, Xiaowen Wang ${ }^{1,3}$, Yuru Kang ${ }^{1,3}$ and Aiqin Wang 1,3,*(1) \\ 1 Key Laboratory of Clay Mineral Applied Research of Gansu Province, Center of Eco-Materials and Green \\ Chemistry, Lanzhou Institute of Chemical Physics, Chinese Academy of Sciences, Lanzhou 730000, China; \\ seli17@licp.cas.cn (S.L.); wangxw@licp.cas.cn (X.W.); yurukang@licp.cas.cn (Y.K.) \\ 2 Center of Materials Science and Optoelectronics Engineering, University of Chinese Academy of Sciences, \\ Beijing 100049, China \\ 3 Center of Xuyi Palygorskite Applied Technology, Lanzhou Institute of Chemical Physics, \\ Chinese Academy of Sciences, Xuyi 211700, China \\ * Correspondence: mubin@licp.cas.cn (B.M.); aqwang@licp.cas.cn (A.W.); \\ Tel.: +86-931-486-8118 (B.M.); Fax: +86-931-496-8019 (B.M.)
}

Received: 3 September 2020; Accepted: 15 October 2020; Published: 18 October 2020

check for updates

\begin{abstract}
Eco-friendly betanin/clay minerals hybrid materials with good stability were synthesized by combining with adsorption, grinding, and heating treatment using natural betanin extracted from beetroot and natural 2:1 type palygorskite or 1:1 type halloysite. After incorporation of clay minerals, the thermal stability and solvent resistance of natural betanin were obviously enhanced. Due to the difference in the structure of palygorskite and halloysite, betanin was mainly adsorbed on the outer surface of palygorskite or halloysite through hydrogen-bond interaction, but also part of them also entered into the lumen of Hal via electrostatic interaction. Compared with palygorskite, hybrid materials prepared with halloysite exhibited the better color performance, heating stability and solvent resistance due to the high loading content of betanin and shielding effect of lumen of halloysite.
\end{abstract}

Keywords: palygorskite; halloysite; betanin; hybrid materials; stability

\section{Introduction}

There has been a long history in the applications of natural plant pigments as colorants for use in the fiber, pottery, paints, and murals, even dating back to prehistoric times [1-6]. Several centuries ago, the Mayans in ancient Mesoamerica invented the well-known Maya blue with bright color and excellent stability, which was commonly used in pottery and mural paintings during the late pre-Spanish period [7-9]. With the development of the characterization techniques and deeper cognition about interaction mechanisms of Maya blue, much progress has been made in the preparation of synthetic substitutes for natural pigments. Although man-made pigments bring great commercial benefits, they will produce persistent organic pollutants or carcinogens in the production process.

In recent years, the dye industry has been forced to gradually ban the production of potentially toxic dyes or pigments $[10,11]$, and natural plant pigments have become the focus once again due to the abundance in nature, low toxicity, good biocompatibility and biodegradability, and no oncogenic hazard $[4,12,13]$. Betalains are water-soluble natural plant pigment containing nitrogen and responsible for the deep yellow or red color of beetroot [14-17]. Betanin is the main ingredient in betalain, which provides vivid colors for food products as an eco-friendly and safe additive, such as ice cream, yogurt, and fudge, enhancing the visual effects and promoting consumption [16,18-20]. However, it has never been found in the same plant as anthocyanin in the plant kingdom. Due to the antioxidative, 
anti-inflammatory, and anticarcinogenic activities, natural betanin pigment has significant curative effect on the chronic diseases including inflammation, diabetes, cancer, and neurological health $[19,21,22]$. Increasingly the importance of natural plant pigments toward human health and the environment is being realized, but it is still a challenge to resolve the innate instability and sensitivity against environmental factors (e.g., light, oxygen, $\mathrm{pH}$ and metal ions), and fast degradation, which can result in a loss of colors and properties of these natural pigments $[15,20,23-26]$. Amjadi et al. studied the inclusion of this bioactive compound in liposomal nanocarriers to improve its digestive stability, antioxidant activity and oral bioavailability $[20,27]$. However, liposomes have low physical-chemical resistibility and easily degraded at the acidic or high-temperature circumstance [28].

Clay minerals have high specific surface area, cation exchange capacity and excellent adsorption properties [29-32]. In addition, different clay minerals have different morphologies, structures, chemical compositions, and properties [33-35]. Therefore, the eco-friendly natural clay minerals have become the focus of the relevant researches on the loading of natural pigments in the last few years, and the interaction between clay minerals and natural pigments is explored and guide to improve the properties of natural pigments. Among them, palygorskite (Pal) is a naturally rod-like hydrated magnesium aluminum phyllosilicate clay mineral with a 2:1 ribbon-layer structure composed of two continuous silica-oxygen tetrahedron sheets and one discontinuous metal-oxygen octahedron sheet [36-39]. One of the most classic applications of Pal is to synthesize Maya blue pigments as an inorganic host of the stabilizing natural indigo dyes. By contrast, halloysite (Hal) is a natural hollow tubular clay mineral with the external diameter of 20-60 nm, inner lumen larger than $10 \mathrm{~nm}$, and the relatively low surface hydroxyl group density [40-43]. As a dioctahedral 1:1 clay mineral, $\mathrm{Hal}$ is composed of the one tetrahedral $\mathrm{SiO}_{4}$ sheet and one octahedral gibbsite $\mathrm{Al}(\mathrm{OH})_{3}$ sheet $[44,45]$. Interestingly, the surface charge of $\mathrm{Hal}$ is the result of the interaction between the negatively charged outer layer (siloxane groups) and the positively charged inner surface (aluminol groups) in the range of $\mathrm{pH}$ 2-8 [46,47]. At present, our group has successfully synthesized a series of acid/base reversible allochroic anthocyanin/clay minerals hybrid pigments based on anthocyanin natural molecules and clay minerals (Pal, Hal, sepiolite, kaolinite, and montmorillonite) [35,39]. However, the studies on the natural anionic pigments and clay minerals are rarely reported.

Based on above background, the hybrid materials with the expected stability were obtained by loading betanin using Pal and Hal by adsorption, grinding and heating treatment. The environmental stability and possible stability mechanism between clay minerals and betanin molecules were systematically compared and studied in this paper.

\section{Experimental}

\subsection{Materials}

Pal was obtained from Guanshan Mine, Anhui Province, China, and the main chemical compositions comprised of $\mathrm{Al}_{2} \mathrm{O}_{3}(8.28 \%), \mathrm{Na}_{2} \mathrm{O}(2.15 \%), \mathrm{CaO}(1.28 \%), \mathrm{MgO}(12.29 \%), \mathrm{SiO}_{2}(58.05 \%)$, $\mathrm{K}_{2} \mathrm{O}(0.92 \%)$, and $\mathrm{Fe}_{2} \mathrm{O}_{3}(5.04 \%)$. Hal was provided by Zhengzhou Jinyangguang Ceramics Co., Ltd., Zhengzhou, China, and the main chemical compositions included $\mathrm{Al}_{2} \mathrm{O}_{3}(29.49 \%), \mathrm{Na}_{2} \mathrm{O}(0.07 \%)$, $\mathrm{CaO}(0.08 \%), \mathrm{MgO}(0.39 \%), \mathrm{SiO}_{2}(42.56 \%), \mathrm{K}_{2} \mathrm{O}(0.85 \%)$, and $\mathrm{Fe}_{2} \mathrm{O}_{3}(1.37 \%)$. Hal was ground and treated with $4 \% \mathrm{HCl}$ (wt.\%), and then filtered by passing through a 200 -mesh sieve and dried. Betanin (red beet extract diluted with dextrin) was provided by Tokyo chemical industry Co., Ltd., Tokyo, Japan.

\subsection{Preparation of Betanin/Clay Mineral Hybrid Materials}

At first, $0.75 \mathrm{~g}$ of betanin was completely dispersed into $40 \mathrm{~mL}$ of distilled water with a $\mathrm{pH}$ of 2.0 adjusted by $\mathrm{HCl}$. Then, $1 \mathrm{~g}$ of Pal or Hal were slowly added to the above mixture and magnetically stirred for $2 \mathrm{~h}$, respectively, followed by oscillation with $200 \mathrm{rpm}$ at $30^{\circ} \mathrm{C}$ for $24 \mathrm{~h}$ in a constant temperature shaker (THZ-98A, INESA, Shanghai, China) to reach the adsorption equilibrium. Then, the products were separated by centrifugation at $4000 \mathrm{rpm}$ for $15 \mathrm{~min}$. Subsequently, the wet 
precipitation was washed with $40 \mathrm{~mL}$ of distilled water for $5 \mathrm{~min}$ and then centrifuged at $4000 \mathrm{rpm}$ for $15 \mathrm{~min}$. The obtained wet betanin/Pal or betanin/Hal samples were first dried at $40{ }^{\circ} \mathrm{C}$ for $5 \mathrm{~h}$ in a vacuum drying oven, and then ground in a mortar for $30 \mathrm{~min}$, respectively. After that, the samples were treated at $120^{\circ} \mathrm{C}$ for $4 \mathrm{~h}$. Finally, the betanin/Pal and betanin/Hal hybrid materials were obtained after screening through a 100 mesh sieve, respectively. It should be noted that the above operations were carried out in dark conditions.

\subsection{Stability Tests}

The thermal stability of the as-prepared hybrid materials was tested using a STA449F3 simultaneous thermal analyzer (NETZSCH-Gerätebau GmbH, Selb, Germany) in the temperature range from 30 to $550{ }^{\circ} \mathrm{C}$ with a heating rate of $10{ }^{\circ} \mathrm{C} / \mathrm{min}$ under nitrogen atmosphere. In order to further evaluate the thermal stability of the two samples, $0.04 \mathrm{~g}$ of betanin/Pal and betanin/Hal were successively placed in an oven at $90,120,150$, and $180^{\circ} \mathrm{C}$ for $60 \mathrm{~min}$ to conduct heat resistance test. The thermal stability of the samples was evaluated by comparing the colorimetric values before and after treatment at different temperatures.

The stability differences of the betanin/Pal and betanin/Hal hybrid materials were also evaluated by immersing in distilled water, acidic, ethanol and basic solutions, respectively. Typically, $0.04 \mathrm{~g}$ of samples were dispersed into $20 \mathrm{~mL}$ of distilled water, $0.1 \mathrm{M} \mathrm{HCl}$, and $0.1 \mathrm{M} \mathrm{NaOH}$, respectively, and then vibrated at $120 \mathrm{rpm}$ and $25^{\circ} \mathrm{C}$ for $24 \mathrm{~h}$ in a constant temperature shaker. After centrifugation at $4000 \mathrm{rpm}$ for $15 \mathrm{~min}$, the wet precipitation was completely dried in a vacuum drying oven at $40{ }^{\circ} \mathrm{C}$, followed by the colorimetric values of the dried samples before and after treatment in the above three solutions were measured to study the chemical stability.

\subsection{Characterizations}

The Fourier transform infrared (FTIR) spectra of samples were recorded on a Nicolet NEXUS FTIR spectrometer (Nicolet iS50, Thermo Scientific, Bartlesville, OK, USA) using KBr pellets in wavenumber range of 400-4000 $\mathrm{cm}^{-1}$. The X-ray diffraction patterns (XRD) were record on an $X^{\prime}$ pert $\mathrm{PRO}$ diffractometer using the $\mathrm{Cu}-\mathrm{K} \alpha$ radiation in the range of $2 \theta=3-80$ at $40 \mathrm{kV}$ and $40 \mathrm{~mA}$ at a scanning rate of $2 \% \mathrm{~min}$. The morphologies were taken using the field emission transmission electron microscopy (TEM, Tecnai G 2 F20 S-TWIN TMP, Hillsboro, OR, USA) after the sample was dispersed ultrasonically in anhydrous ethanol and dropped onto a micro grid. The surface area and pore volume of samples were measured using the Accelerated Surface Area and Porosimetry System (Micromeritics, ASAP2020, Atlanta, GA, USA) at $-196{ }^{\circ} \mathrm{C}$ with $\mathrm{N}_{2}$ as an adsorbate. The zeta potentials were measured on a Malvern Zetasizer Nano system (ZEN3600, Malvern, UK) with a $633 \mathrm{~nm}$ He-Ne laser irradiated, in which $0.05 \mathrm{~g}$ of sample was dispersed into $10 \mathrm{~mL}$ of deionized water and sonicated for 20 min before measurement of zeta potential. The surface composition and the chemical state of the samples were investigated by X-ray photoelectron spectroscopy (XPS, ESCALAB 250Xi, ThermoFisher Scientific, Waltham, MA, USA), and all the binding energies were referenced to the C1s peak at $284.8 \mathrm{eV}$ of the surface adventitious carbon. Survey scans were obtained in the $0-1400 \mathrm{eV}$ range, and the high-resolution scanning was recorded for the C1s, N1s, O1s, Si2p, Mg1s and Al2p regions. Thermal gravimetric analysis (TGA) was obtained on a STA449F3 simultaneous thermal analyzer (NETZSCH-Gerätebau $\mathrm{GmbH}$, Wittelsbacherstrasse, Berlin, Germany) at a heating rate of $10{ }^{\circ} \mathrm{C} \mathrm{min}^{-1}$ under a $\mathrm{N}_{2}$ atmosphere. The colorimetric values and reflectance spectra of all samples were calculate on a Color-Eye automatic differential colorimeter (X-Rite, Ci 7800, Pantone Inc., Carlstadt, NJ, USA) according to the Commission International de $1^{\prime}$ Eclairage (CIE) $1976 L^{*} a^{*} b^{*}$ colorimetric method, in which $L^{*}$ was the color lightness ranging from black (0) to white (100), while $a^{*}$ and $b^{*}$ represented the hue with positive and negative values mean red to green and yellow to blue, respectively. The colorimetric values of each sample were tested parallel for three times. The chemical composition was collected from E3 X-ray fluorescence spectrometer (PANalytical, Almelo, The Netherlands). The surface elemental compositions of hybrid materials were determined using a Kevex energy dispersive spectrometer (EDS). 


\section{Results and Discussion}

\subsection{Preparation and Characterization of the Hybrid Materials}

The preparation process of betanin/clay mineral hybrid materials are shown in Scheme 1, and the main preparation processes includes adsorption, grinding and heating treatment. Typically, the first step is to load the betanin molecules onto Pal or Hal through a simple adsorption process $[39,48]$. Subsequently, the grinding and heating treatment are applied to promote the physical and chemical interaction between betanin and clay minerals [39,48]. Among them, the application of heating treatment helps to remove the water molecules partially located in the clay minerals, resulted in facilitating the fixation of betanin molecules on clay minerals and improving their stability $[1,8,9,35,39]$. The natural Pal and Hal are white and light yellow (Table S1), respectively, and hybrid materials present pink color after incorporation of betanin, which indicates that betanin has been successfully loaded on the clay minerals $[13,35,39]$.

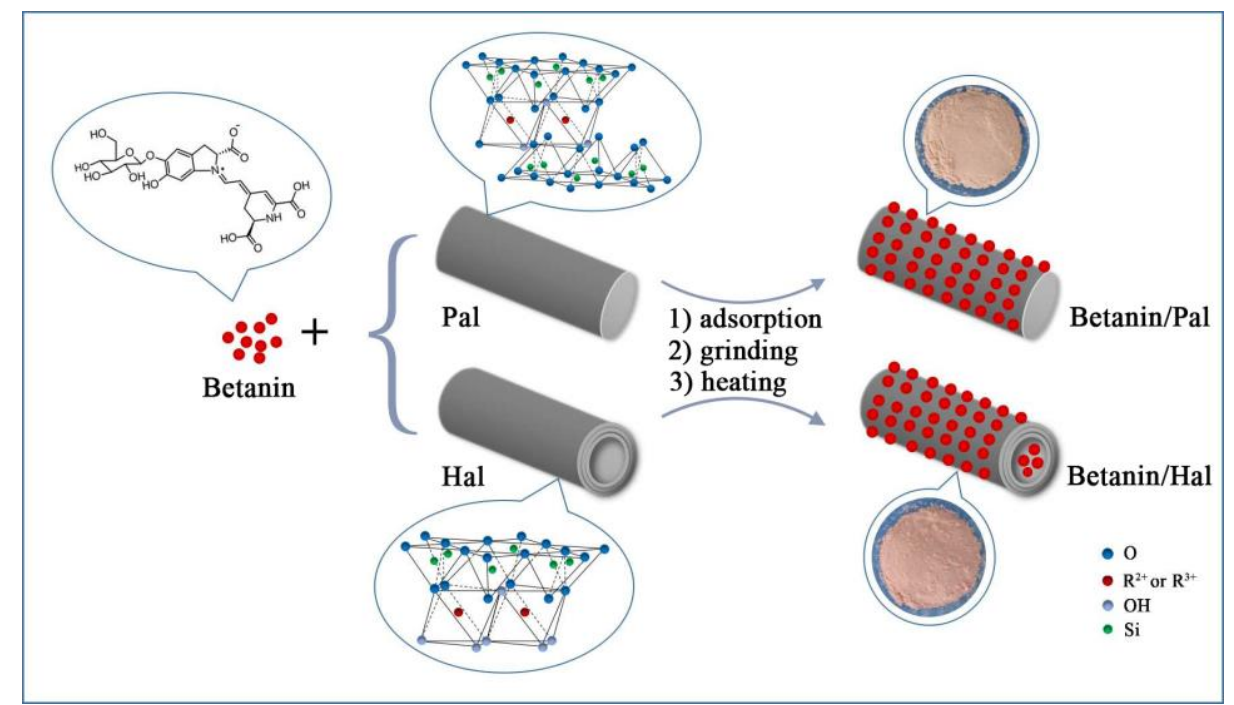

Scheme 1. Schematic illustration for preparation of betanin/Pal and betanin/Hal hybrid materials.

TEM micrographs of betanin/Pal and betanin/Hal hybrid materials exhibit that the typical morphologies of clay minerals is remained after the introduction of betanin molecules (Figure 1a,b) [39,42,48-50]. Among them, betanin/Pal hybrid materials present the rod-like morphology, while betanin/Hal hybrid materials exhibit the hollow tubular morphology with the external diameter of 20-60 nm and inner lumen larger than $10 \mathrm{~nm}$. It indicates that the preparation process has no obvious effect on the morphologies of the involved clay minerals.

EDS analysis is used to reveal the surface chemical compositions of betanin/Pal and betanin/Hal samples (Figure S1), and their atomic percent with different elements is presented in Figure 1c,d, respectively. The $\mathrm{O}, \mathrm{Si}, \mathrm{Mg}, \mathrm{Al}, \mathrm{Fe}$, and $\mathrm{Ca}$ elements are derived from Pal and Hal [34,51,52]. Furthermore, the presence of $\mathrm{C}$ and $\mathrm{N}$ demonstrates the successful loading of betanin on Pal and Hal. Among them, the detectable amounts of $\mathrm{C}$ and $\mathrm{N}$ on the Pal surface are $18.01 \%$ and $10.89 \%$, respectively, which are higher than that of betanin/Hal (9.82\% and $7.92 \%)$, indicating that the amount of betanin loading on the Pal surface is higher than that on the external surface of Hal.

The pore structural parameters of clay minerals and the corresponding hybrid materials are listed in Table 1. Compared with raw clay minerals, the specific surface areas $\left(S_{B E T}\right)$ of betanin/Pal sample decreases significantly from $185.85 \mathrm{~m}^{2} / \mathrm{g}$ to $129.19 \mathrm{~m}^{2} / \mathrm{g}$ while that of betanin/Hal hybrid materials decreases by only $9.81 \mathrm{~m}^{2} / \mathrm{g}$ after the incorporation of betanin, indicating that betanin molecules are mainly loaded on the external surface of clay minerals [39,48]. In addition, the total pore volume ( $V_{\text {total }}$ ) of betanin/Hal sample also reduces to $0.0312 \mathrm{~cm}^{3} / \mathrm{g}$, whereas the $V_{\text {total }}$ values of betanin/Pal 
hybrid materials have no significant change. This fact suggests that some betanin molecules might be embedded in the lumen of Hal, resulting in the reduction of the $V_{\text {total }}$ values of Hal.
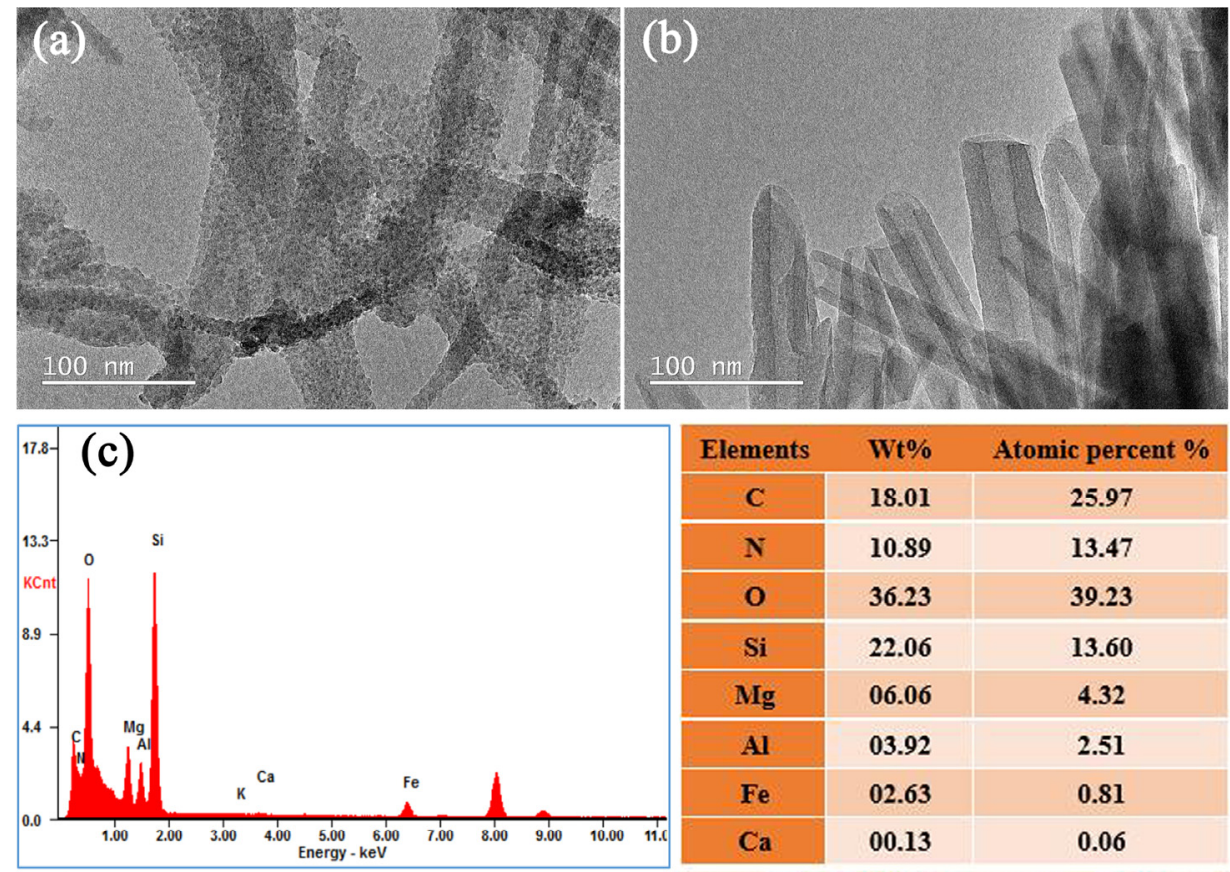

\begin{tabular}{|c|c|c|}
\hline Elements & $\mathbf{W t} \%$ & Atomic percent \% \\
\hline $\mathrm{C}$ & 18.01 & 25.97 \\
\hline $\mathrm{N}$ & 10.89 & 13.47 \\
\hline $\mathrm{O}$ & 36.23 & 39.23 \\
\hline $\mathrm{Si}$ & 22.06 & 13.60 \\
\hline $\mathrm{Mg}$ & 06.06 & 4.32 \\
\hline $\mathrm{Al}$ & 03.92 & 2.51 \\
\hline $\mathrm{Fe}$ & 02.63 & 0.81 \\
\hline $\mathrm{Ca}$ & 00.13 & 0.06 \\
\hline
\end{tabular}

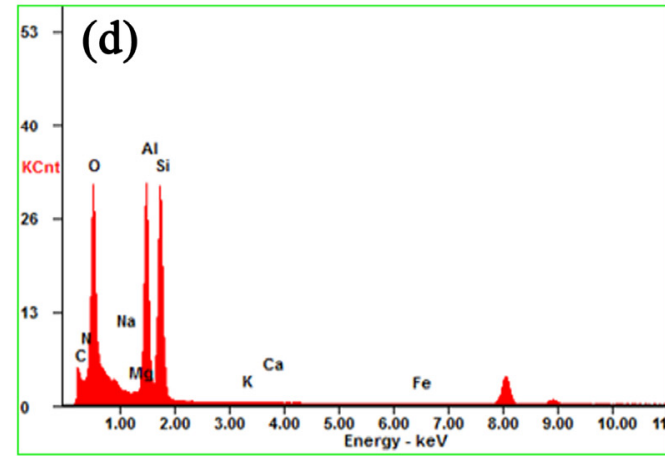

\begin{tabular}{|c|c|c|}
\hline Elements & Wt $\%$ & Atomic percent $\%$ \\
\hline $\mathrm{C}$ & 9.82 & 15.18 \\
\hline $\mathrm{N}$ & 7.92 & 10.49 \\
\hline $\mathrm{O}$ & 38.34 & 44.46 \\
\hline $\mathrm{Si}$ & 21.88 & 14.45 \\
\hline $\mathrm{Mg}$ & 1.19 & 0.91 \\
\hline $\mathrm{Al}$ & 19.07 & 13.11 \\
\hline $\mathrm{Fe}$ & 0.07 & 0.02 \\
\hline $\mathrm{Ca}$ & 00.02 & 0.01 \\
\hline
\end{tabular}

Figure 1. TEM images and EDS spectra of $(\mathbf{a}, \mathbf{c})$ betanin/Pal, and $(\mathbf{b}, \mathbf{d})$ betanin/Hal hybrid materials.

Table 1. Pore structural parameters of the raw clay minerals and hybrid materials.

\begin{tabular}{ccccc}
\hline Samples & $S_{\text {BET }}\left(\mathrm{m}^{2} / \mathrm{g}\right)$ & $S_{\text {micro }}\left(\mathrm{m}^{2} / \mathrm{g}\right)$ & $S_{\text {ext }}\left(\mathrm{m}^{2} / \mathrm{g}\right)$ & $V_{\text {total }}\left(\mathrm{cm}^{3} / \mathrm{g}\right)$ \\
\hline Pal & 185.85 & 26.93 & 158.93 & 0.4243 \\
Betanin/Pal & 129.19 & 11.40 & 117.79 & 0.4288 \\
Hal & 58.10 & 1.43 & 56.67 & 0.2064 \\
Betanin/Hal & 48.29 & - & 52.43 & 0.1752 \\
\hline
\end{tabular}

As shown in Figure 2, the zeta potentials of betanin at lower $\mathrm{pH}$ is $-26.43 \mathrm{mV}$, which is consistent with previous report [53]. After adding betanin, the zeta-potential value of Pal increases slightly from $-20.60 \mathrm{mV}$ to $-17.80 \mathrm{mV}$, which is consistent with the results of the stabilization of betacyanins by food grade anionic polysaccharides [53]. Interestingly, the surface charge of Hal is the result of the interaction between the negatively charged external surface $\left(\mathrm{SiO}_{4}\right)$ and the positiviely charged inner surface $\left(\mathrm{AlO}_{6}\right)$ in the range of $\mathrm{pH} 2-8[13,42,46]$. Therefore, the anion pigment may enter into the lumen of Hal during the preparation process, and the electrostatic interactions occurs within the Hal nanotubes, resulting in a reduction in the positive charge of Hal, and thus the zeta potentials of the hybrid material decreases significantly from $-21.83 \mathrm{mV}$ to $-32.93 \mathrm{mV}$. It is also possible that the negatively charged outer surface electrostatically interacts with the positively charged fragments of 
betanin due to its zwitterionic property. Thus, the carboxyl groups are facing outward, which leads to decreasing in the zeta potential.

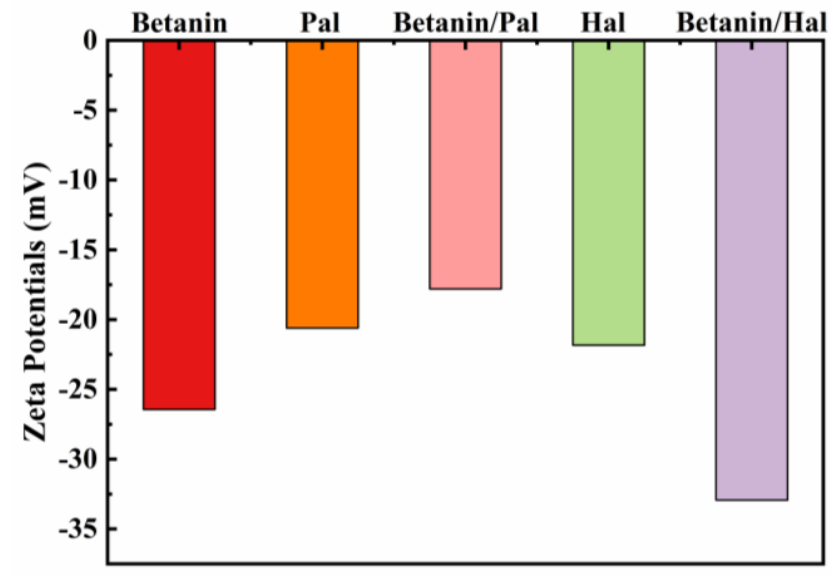

Figure 2. Zeta potentials of betanin, clay minerals and hybrid materials.

As shown in Figure 3a, the XRD patterns of Pal and Hal present typical characteristic diffraction peaks accompanied by a small amount of impurities such as mica and dolomite [48,54]. Pal shows three strong reflection peaks in $2 \theta=8.42^{\circ}(d=10.49 \AA), 13.79^{\circ}(d=16.42 \AA)$ and $19.88^{\circ}(d=4.46 \AA)$, corresponding to (110), (200) and (040) crystal planes [55]. Hal has typical diffraction peaks at $2 \theta=12.04^{\circ}$ $(d=7.34 \AA)$ and $24.72^{\circ}(d=3.60 \AA)$ corresponding to the $(001)$ and $(002)$ planes [56,57]. Compared with the XRD patterns of clay minerals and corresponding hybrid materials, it is found that the XRD patterns of hybrid materials are similar to that of the corresponding clay minerals, no emergence of a new diffraction peak and no obvious layer spacing changes of Pal and Hal in (110) and (001), respectively.
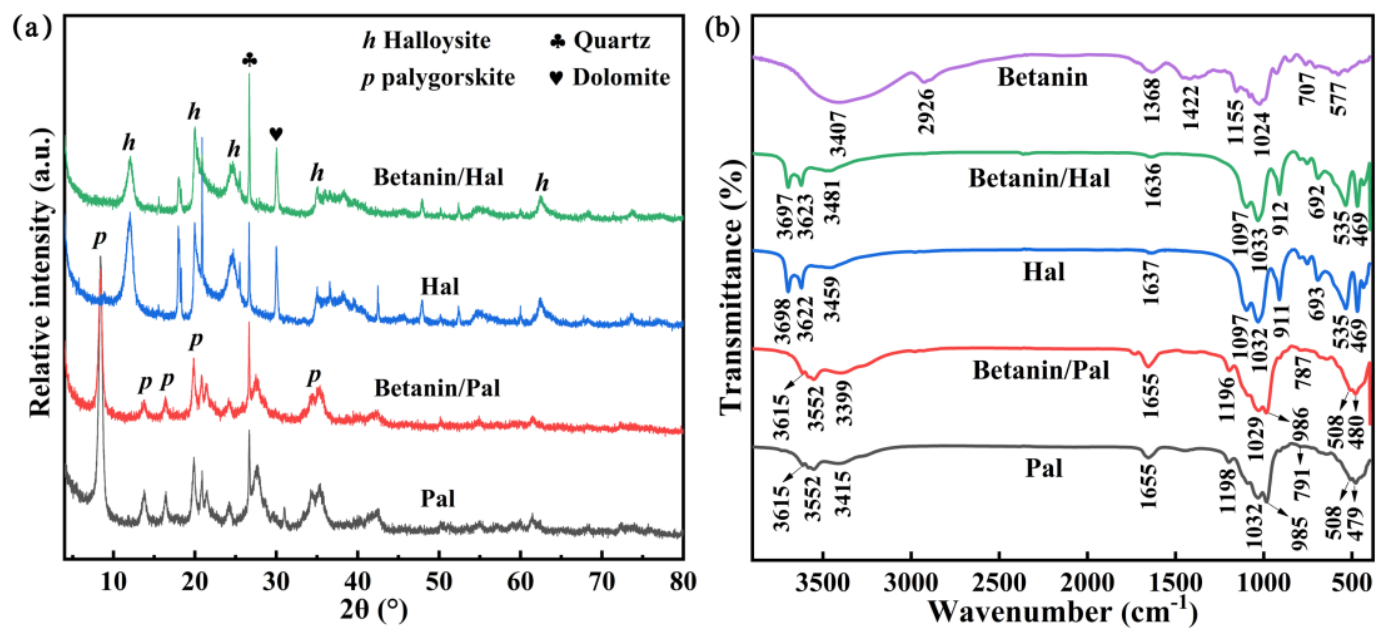

Figure 3. (a) XRD patterns and (b) FTIR spectra of betanin, clay minerals and hybrid materials.

The FTIR spectra of clay minerals, hybrid materials and natural betanin molecules are shown in Figure 3b. In case of clay minerals, the characteristic absorption bands are presented in Figure 3b. The absorption bands around $3700-3500 \mathrm{~cm}^{-1}$ and $3400-3300 \mathrm{~cm}^{-1}$ are mainly due to the stretching vibration of the O-H group of the structural hydroxyl group and water molecule [57,58]. In FTIR spectra of Pal, the absorption band at about $1600 \mathrm{~cm}^{-1}$ corresponds to the antisymmetric stretching vibration of zeolite water and adsorbed water $[48,59,60]$. The absorption band of $791 \sim 1198 \mathrm{~cm}^{-1}$ is the anti-symmetric stretching vibration peak of Si-O bond $[59,61]$. The bands at 508 and $497 \mathrm{~cm}^{-1}$ are assigned to the tetrahedral Si-O deformation and bending vibration, respectively [62]. In FTIR 
spectrum of Hal, 1637 and $911 \mathrm{~cm}^{-1}$ represent the bending vibrations of $\mathrm{H}_{2} \mathrm{O}$ and the deformation of $-\mathrm{OH}$ [54,57], while 1097 and $1032 \mathrm{~cm}^{-1}$ is attributed to the bending vibration peaks of Si-O and $\mathrm{Si}-\mathrm{O}-\mathrm{Si}$, respectively $[54,56]$. In the case of betanin, the absorption band at $3400 \mathrm{~cm}^{-1}$ is attributed to the stretching vibration of $-\mathrm{OH}$, the absorption band at $2926 \mathrm{~cm}^{-1}$ belongs to the stretching vibration of $\mathrm{C}-\mathrm{H}$, and two vibration peaks at $1638 \mathrm{~cm}^{-1}$ and $1422 \mathrm{~cm}^{-1}$ are ascribed to the $-\mathrm{COOH}$ group and the aromatic $-\mathrm{CH}$ group, respectively [63]. The symmetric stretching vibration of $\mathrm{C}-\mathrm{O}-\mathrm{C}$ appears at $1024 \mathrm{~cm}^{-1}$ [64], while the absorption peak at $707 \mathrm{~cm}^{-1}$ confirms the existence of $\mathrm{N}-\mathrm{H}$ [65]. In the FTIR spectrum of hybrid materials, the absorption peaks of the stretching vibration peaks of $\mathrm{O}-\mathrm{H}$ bonds in Pal and Hal shift from $3415 \mathrm{~cm}^{-1}$ to $3399 \mathrm{~cm}^{-1}$ and from $3459 \mathrm{~cm}^{-1}$ to $3481 \mathrm{~cm}^{-1}$, respectively, which may be due to the hydrogen bond interaction between betanin and clay minerals [27].

The XPS characterization is performed to analyze the existence of surface elements and their chemical states of betanin/Pal and betanin/Hal hybrid materials. As shown in Figure $4 \mathrm{a}$, the signals of Si2p, Al2p, O1s, and C1s are obviously observed from the XPS survey spectra of betanin/Pal and betanin/Hal samples, and Mg1s is only found from the XPS spectra of Pal and betanin/Pal, which is related to the difference in the XRF chemical compositions between Pal and Hal. The $\mathrm{N}$ atoms in the chemical composition of the two hybrid materials are hardly detected (Figure $4 \mathrm{~b}$ and Table S2), which may be due to the fact that the $\mathrm{N}$ element only accounts for $5 \%$ of the relative molecular weight of the betanin molecule. Furthermore, the $\mathrm{C} 1$ s peaks for betanin/Pal and betanin/Hal samples presented at $284.85 \mathrm{eV}$ and $284.83 \mathrm{eV}$, respectively. In addition, the $\mathrm{C} 1 \mathrm{~s}$ spectra of the betanin/Pal and betanin/Hal samples consists of the $\mathrm{C}-\mathrm{C}(\mathrm{C}-\mathrm{H})$ and sp2-C, and the corresponding binding energies are located at about $285.20 \mathrm{eV}$ and $284.65 \mathrm{eV}, 285.02 \mathrm{eV}$ and $284.66 \mathrm{eV}$, respectively (Figure 4c). Therefore, it indicates that hybrid materials are successfully prepared based on betanin and Pal or Hal.

In the case of the high-resolution spectra of Si2p of Pal, the binding energies the surface silanol groups and Si-O bonds increase from $103.15 \mathrm{eV}$ to $103.29 \mathrm{eV}$, and $102.48 \mathrm{eV}$ to $102.72 \mathrm{eV}$ after incorporation of betanin (Figure 4d) [34,66,67], and this change suggests that there is an interaction between the betanin molecules and the surface silanol groups and Si-O of Pal. Meanwhile, the Mg1s binding energy of $\mathrm{Pal}$ increases from $1304.20 \mathrm{eV}$ to $1304.23 \mathrm{eV}$ with the introduction of betanin (Figure 4e), while two peaks of Al2p at $74.95(\mathrm{Al}-\mathrm{OH})$ and $74.53 \mathrm{eV}(\mathrm{Al}-\mathrm{O})$ also shifts to $75.42 \mathrm{eV}$ and $74.61 \mathrm{eV}$, respectively (Figure 4f). It indicates that $\mathrm{Mg}-\mathrm{O}-\mathrm{Si}, \mathrm{Al}-\mathrm{OH}$ and $\mathrm{Al}-\mathrm{O}-\mathrm{Si}$ of Pal may interact with betanin. It is worth noting that the similar phenomenon is also found from Si2p and Al2p of Hal before and after incorporation of betanin (Figure $4 \mathrm{~g}, \mathrm{~h}$ ), it reveals that betanin also interact with the surface silanol groups and the $\mathrm{Al}-\mathrm{OH}$ of the lumen of Hal. Furthermore, the decrease in the intensity of Mg1s and Al2p of of Pal may be due to the leaching of some magnesium and aluminum ions from Pal under acidic conditions, which can be confirmed in Table S2 [66]. 
(a)

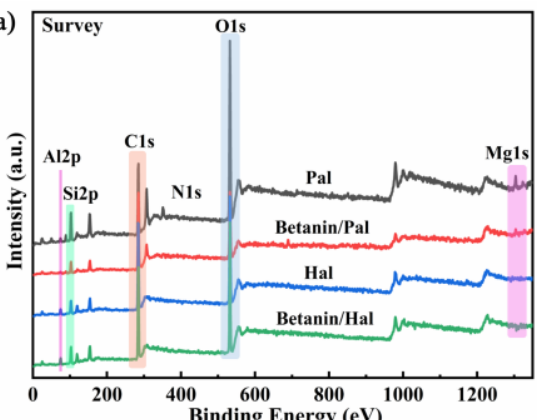

(c)

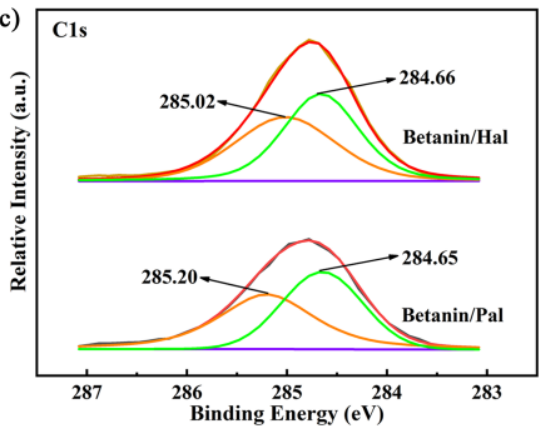

(e)
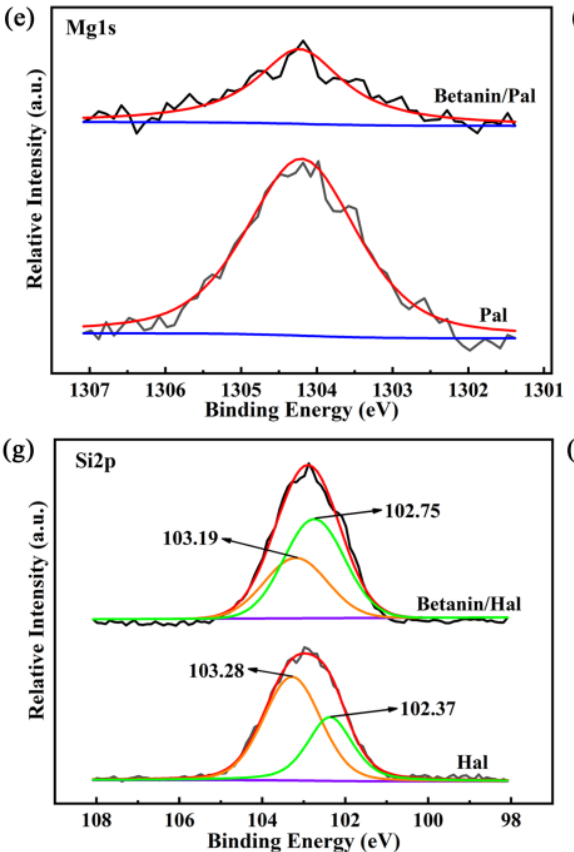
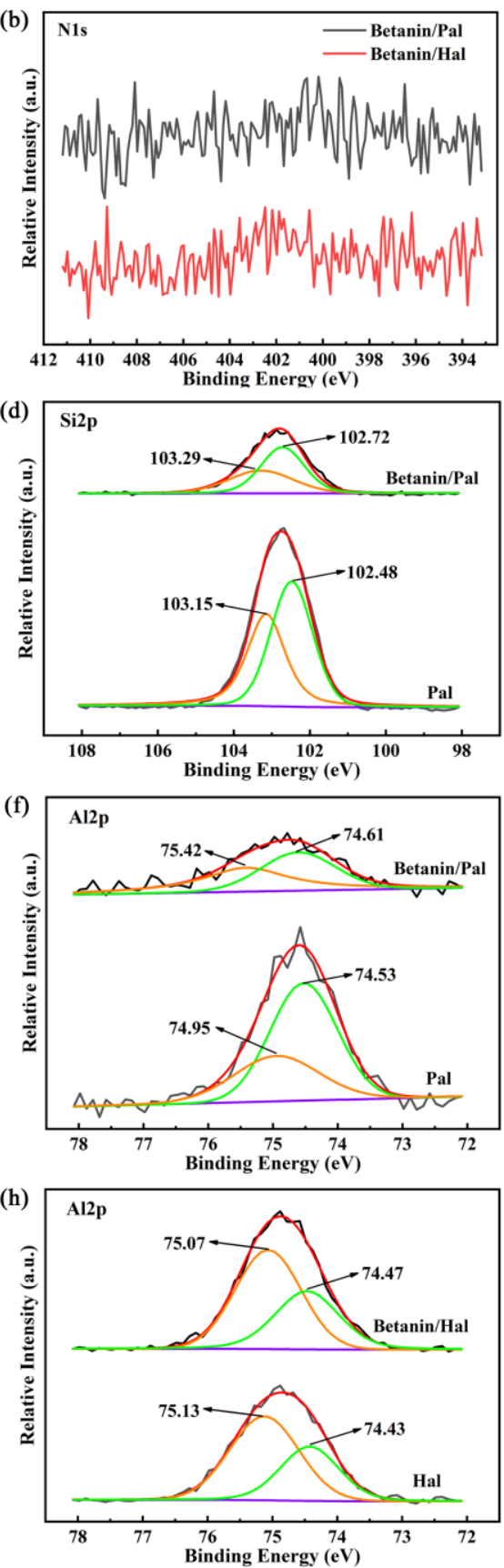

Figure 4. X-ray photoelectron spectra of Pal, betanin/Pal, Hal, betanin/Hal (a) high-resolution scanning spectra of (b) N1s, (c) C1s, (d,e) Si2p, (f,g) Al2p, (h) Mg1s.

\subsection{Thermal and Chemical Stability of the Hybrid Materials}

The DSC-TGA curves of clay minerals, hybrid materials and betanin are shown in Figure 5. As depicted in Figure 5a, clay minerals, hybrid materials and betanin have obvious Endothermic peaks in the DSC curves. As can be seen from Figure $5 b$, natural betanin begins to degrade at room temperature and rapidly lost the weight at about $200{ }^{\circ} \mathrm{C}$, and it presents a maximum loss at $350{ }^{\circ} \mathrm{C}$ suggesting that the degradation of natural pigments basically completes. At $550{ }^{\circ} \mathrm{C}$, the residual mass of betanin is only $25.57 \%$, indicating that natural pigments have poor high temperature resistance. In case of raw $\mathrm{Pal}$, the degradation process occurs in the three stages of $30-550{ }^{\circ} \mathrm{C}$, which are related to the removal of the adsorbed water, zeolitic $\mathrm{H}_{2} \mathrm{O}$, the bound $\mathrm{OH}_{2}$, and part of structural $\mathrm{OH}$, respectively $[39,48,60,62]$. As for raw Hal, it shows an initial slight mass loss from room temperature, which is attributed to the 
evaporation of the physically adsorbed water and the interlayer $\mathrm{H}_{2} \mathrm{O}$. In addition, the weight loss from $400{ }^{\circ} \mathrm{C}$ to $550^{\circ} \mathrm{C}$ is ascribed to the removal of hydroxyl groups of Hal $[13,68,69]$. Obviously, the hybrid material exhibits different degradation behavior to the corresponding clay minerals, which is due to the addition of betanin. The betanin in betanin/Pal and betanin/Hal sample exhibits the obviously low weight loss rate of $1.35 \%$ and $0.30 \%$ at $200{ }^{\circ} \mathrm{C}$, respectively. It is worth noting that the final mass loss of betanin in betanin/Hal (1.31\%) is significantly lower than that of in betanin/Pal (6.07\%). Therefore, the results demonstrate that betanin/Hal presents much better thermal stability than betanin/Pal at higher temperatures. It is possibly due to the stronger physical and chemical interactions between Hal and betanin molecules, and the fact that the small molecules partly enters into the lumen of Hal, resulting in more superior shielding effect.
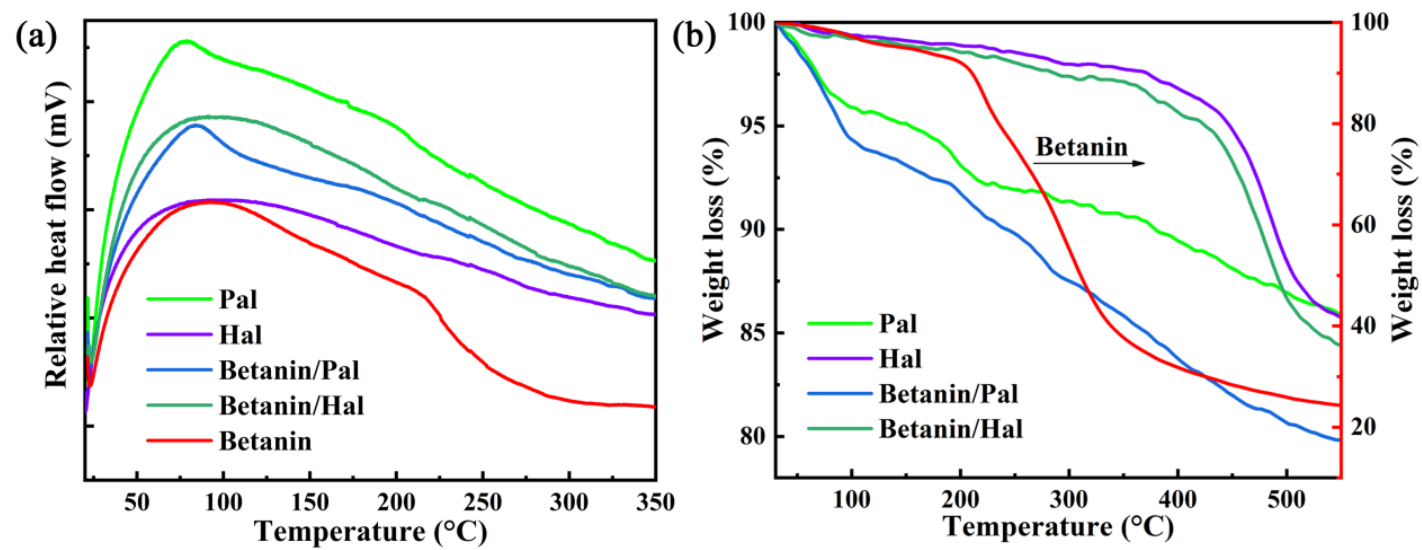

Figure 5. (a) DSC and (b) TGA curves of the raw clay minerals and hybrid materials.

The chromaticity values of betanin and hybrid materials after being successively treated at 90 , 120,150 , and $180{ }^{\circ} \mathrm{C}$ for $60 \mathrm{~min}$ are applied to further evaluate the thermal stability of samples. As shown in Figure $6 \mathrm{a}$, the changes of $L^{*}, a^{*}$, and $b^{*}$ of betanin at lower heating temperature are very obvious, indicating that the thermal stability of betaine is poor. After incorporation of clay minerals, the chromaticity values of the hybrid material changes little within $90^{\circ} \mathrm{C}$ (Figure $6 \mathrm{~b}, \mathrm{c}$ ). As the temperature continues to rise, the $L^{*}$ and $b^{*}$ values of betanin/Pal increase gradually, while the $a^{*}$ values decreases gradually. Compared with betanin and betanin/Pal, betanin/Hal has a smaller change in chromaticity value exhibiting the better thermal stability, as evidenced by digital images of samples at different heating temperatures (Figure S2). It might be due to the fact that betanin is not only adsorbed on the external surface of Hal, but also confined in the lumen [54].
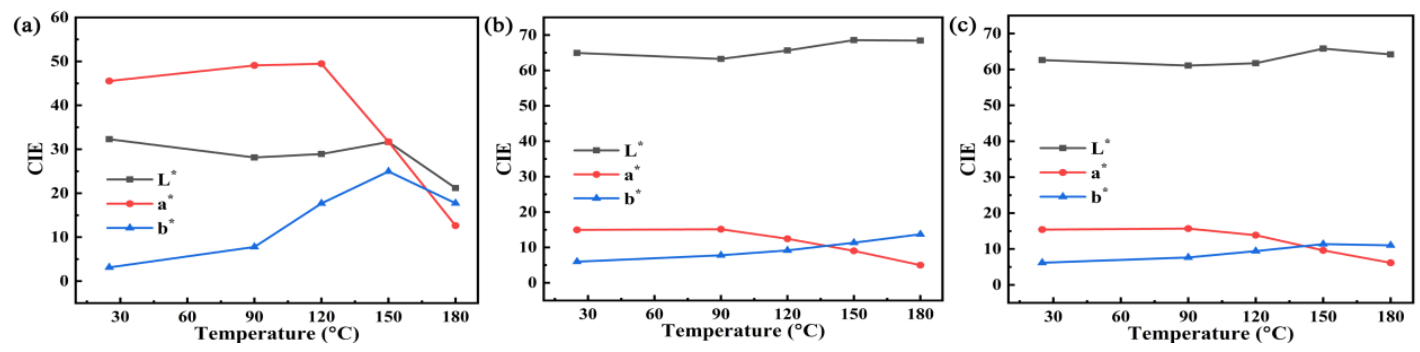

Figure 6. CIE of (a) betanin, (b) betanin/Pal and (c) betanin/Hal at different temperatures.

In addition, the solvent resistance of hybrid material is also evaluated. The colorimetric parameters of hybrid materials before and after being immersed into distilled water, $0.1 \mathrm{M}$ hydrochloric acid and sodium hydroxide for $24 \mathrm{~h}$ are listed in Table 2. As shown in Table 2, the color parameters of betanin/Pal samples before and after immersion in the three solutions are significantly different. After being treated with hydrochloric acid and sodium hydroxide, the $a^{*}$ value decreases significantly to 1.89 
and 1.48, while $b^{*}$ increases from 5.99 to 13.00 and 9.98. The CIE parameters of betanin/Hal hybrid materials change less than those of betanin/Pal samples after being treated with different solutions. Combined with the images of the supernatants after being immersed in the above solutions (Figure S3), it can be concluded that the introduction of Hal is more helpful to improve the stability of natural pigments in distilled water, acid and alkaline solutions.

Table 2. Color parameters of betanin/Pal and betanin/Hal before and after being treated by distilled water, $0.1 \mathrm{M} \mathrm{HCl}$ and $0.1 \mathrm{M} \mathrm{NaOH}$ for $24 \mathrm{~h}$.

\begin{tabular}{ccccccc}
\hline \multirow{2}{*}{$\begin{array}{c}\text { Different } \\
\text { Medium }\end{array}$} & \multicolumn{3}{c}{ Betanin/Pal } & \multicolumn{3}{c}{ Betanin/Hal } \\
\cline { 2 - 7 } & $\boldsymbol{L}^{*}$ & $\boldsymbol{a}^{*}$ & $\boldsymbol{b}^{*}$ & $\boldsymbol{L}^{*}$ & $\boldsymbol{a}^{*}$ & $\boldsymbol{b}^{*}$ \\
\hline $\begin{array}{c}\text { Before } \\
\text { immersion } \\
\text { Distilled }\end{array}$ & $64.94 \pm 0.50$ & $14.96 \pm 0.25$ & $5.99 \pm 0.05$ & $62.64 \pm 0.10$ & $15.43 \pm 0.08$ & $6.18 \pm 0.06$ \\
$\quad$ water & $69.59 \pm 0.07$ & $5.13 \pm 0.01$ & $8.34 \pm 0.02$ & $56.23 \pm 0.01$ & $12.02 \pm 0.01$ & $6.01 \pm 0.01$ \\
$0.1 \mathrm{M} \mathrm{HCl}$ & $73.13 \pm 0.22$ & $1.89 \pm 0.02$ & $13.00 \pm 0.08$ & $59.23 \pm 0.14$ & $6.32 \pm 0.05$ & $11.80 \pm 0.08$ \\
$0.1 \mathrm{M} \mathrm{NaOH}$ & $70.47 \pm 0.01$ & $1.48 \pm 0.02$ & $9.98 \pm 0.02$ & $64.60 \pm 0.12$ & $6.85 \pm 0.01$ & $13.91 \pm 0.09$ \\
\hline
\end{tabular}

It is clear that the color of betanin/Hal after being treated by distilled water, $0.1 \mathrm{M} \mathrm{HCl}$ and $0.1 \mathrm{M}$ $\mathrm{NaOH}$ for $24 \mathrm{~h}$ is much closer to the red area than that of hybrid materials under the same treatment condition (Figure 7a). Furthermore, the characteristic absorption bands in the range of 450-600 nm representing red are attributed to the existence of betanin in the diffuse reflectance spectra (Figure $7 \mathrm{~b}, \mathrm{c})$. The intensity of absorption bands of betanin/Hal samples is larger than that of betanin/Pal samples after being treated using different solvents for $24 \mathrm{~h}$ (Figure $7 \mathrm{~b}, \mathrm{c}$ ). This further confirms that Hal has a better shielding effect on natural pigments toward the external environments.

(a)

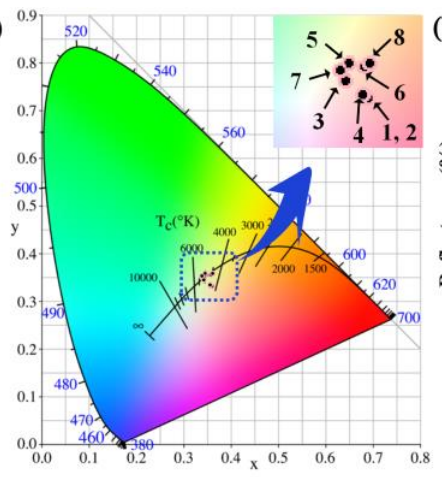

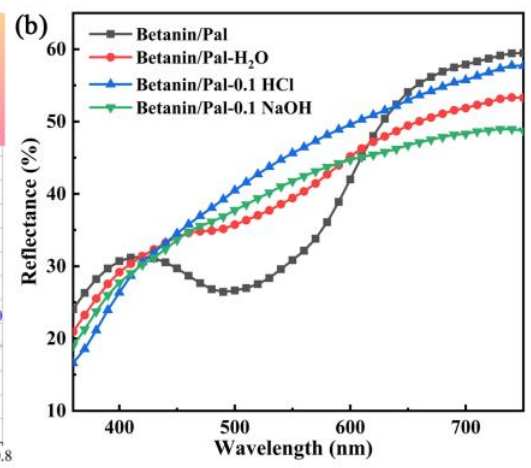

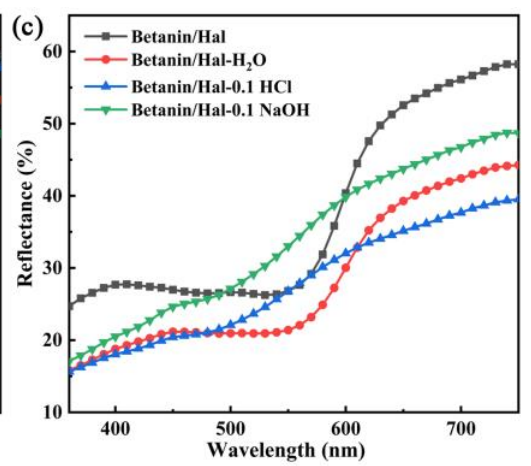

Figure 7. (a) Chromatic CIE coordinates and UV-vis diffuse reflectance spectra of (b) betanin/Pal and (c) betanin/Hal hybrid materials after being treated by distilled water, $0.1 \mathrm{M} \mathrm{HCl}$ and $0.1 \mathrm{M} \mathrm{NaOH}$ for 24 h (1: Betanin/Pal; 2: Betanin/Hal; 3: Betanin/Pal- $\mathrm{H}_{2} \mathrm{O}$; 4: Betanin/Hal- $\mathrm{H}_{2} \mathrm{O}$; 5: Betanin/Pal-HCl; 6: Betanin/Hal-HCl; 7: Betanin/Pal-NaOH; 8: Betanin/Hal-NaOH).

\section{Conclusions}

The betanin/clay mineral hybrid materials were successfully prepared using the natural betanin molecules and Pal or Hal. It was found that the thermal and chemical stability of the betanin molecule was also obviously improved after incorporation of clay minerals, and the betanin/Hal hybrid materials presented the better color performance $\left(L^{*}=62.64, a^{*}=15.43, b^{*}=6.18\right)$ than betanin/Pal samples $\left(L^{*}=64.94, a^{*}=14.96, b^{*}=5.99\right)$. Due to the differences in the structure of clay minerals, the betanin molecules were mainly loaded on the surface of Pal or Hal, but part of betanin also entered into the lumen of Hal, and thus betanin/Hal hybrid materials exhibits the better color property and stability against the external environmental factors. Furthermore, the as-prepared stable hybrid materials may 
be a potential candidate as eco-friendly antibacterial agent to be applied in relevant fields combining with the inherent antibacterial and nontoxic components.

Supplementary Materials: The following are available online at http://www.mdpi.com/1996-1944/13/20/4649/s1, Table S1: Color parameters of pure betanin, Pal and Hal; Table S2: Chemical compositions and their atomic percents of Pal, betanin/Pal, Hal, and betanin/Hal; Figure S1: The element mapping images of (A) betanin/Pal and (B) betanin/Hal: (a) C, (b) N, (c) O, (d) Si, (e) Mg, (f), Al (g) Fe, (h) Ca; Figure S2: Digital images of the pure betanin, betanin/Pal and betanin/Hal at different heating temperatures; Figure S3: Digital images of the pure betanin and betanin desorbed from the betanin/Pal and betanin/Hal hybrid materials after being immersed for $24 \mathrm{~h}$ in (a) distilled water, (b) $0.1 \mathrm{M} \mathrm{HCl}$ and (c) $0.1 \mathrm{M} \mathrm{NaOH}$, respectively.

Author Contributions: A.W. and S.L. designed the experiments; S.L. performed the experiments and characterization analysis; B.M., X.W., and Y.K. assisted with the experimental work; S.L. wrote the original draft manuscript; A.W. and B.M. reviewed and edited the manuscript. All authors have read and agreed to the published version of the manuscript.

Funding: This research was funded by the Major Projects of the National Natural Science Foundation of Gansu, China (18JR4RA001), and Youth Innovation Promotion Association of CAS (2017458).

Conflicts of Interest: The authors declare no competing financial interest.

\section{References}

1. Jose-Yacaman, M.; Rendón, L.; Arenas, J.; Puche, M.C.S. Maya Blue Paint: An Ancient Nanostructured Material. Science 1996, 273, 223-225. [CrossRef] [PubMed]

2. Cristea, D.; Vilarem, G. Improving light fastness of natural dyes on cotton yarn. Dye. Pigment. 2006, 70, 238-245. [CrossRef]

3. Leona, M. Microanalysis of organic pigments and glazes in polychrome works of art by surface-enhanced resonance Raman scattering. Proc. Natl. Acad. Sci. USA 2009, 106, 14757-14762. [CrossRef] [PubMed]

4. Mirjalili, M.; Nazarpoor, K.; Karimi, L. Eco-friendly dyeing of wool using natural dye from weld as co-partner with synthetic dye. J. Clean. Prod. 2011, 19, 1045-1051. [CrossRef]

5. Berrie, B.H. Rethinking the History of Artists' Pigments Through Chemical Analysis. Annu. Rev. Anal. Chem. 2012, 5, 441-459. [CrossRef]

6. Mohd-Nasir, H.; Abd-Talib, N.; Mohd-Setapar, S.H.; Wong, L.P.; Idham, Z.; Casillas, A.C.; Ahmad, A. Natural colorants from plants for wellness industry. Int. J. Pharm. Sci. Rev. Res. 2018, 9, 836-843. [CrossRef]

7. Van Olphen, H. Maya Blue: A Clay-Organic Pigment? Sciences 1966, 154, 645-646. [CrossRef]

8. Hubbard, B.; Kuang, W.; Moser, A.; Facey, G.A.; Detellier, C. Structural study of Maya Blue: Textural, thermal and solidstate multinuclear magnetic resonance characterization of the palygorskite-indigo and sepiolite-indigo adducts. Clays Clay Miner. 2003, 51, 318-326. [CrossRef]

9. Ouellet-Plamondon, C.M.; Aranda, P.; Favier, A.; Habert, G.; Van Damme, H.; Ruiz-Hitzky, E. The Maya blue nanostructured material concept applied to colouring geopolymers. RSC Adv. 2015, 5, 98834-98841. [CrossRef]

10. Roriz, C.L.; Heleno, S.A.; Carocho, M.; Rodrigues, P.; Pinela, J.; Dias, M.I.; Fernandes, I.P.; Barreiro, M.F.; Morales, P.; Barros, L.; et al. Betacyanins from Gomphrena globosa L. flowers: Incorporation in cookies as natural colouring agents. Food Chem. 2020, 329, 127178. [CrossRef]

11. Zhang, D.; Cheng, X.; Sun, D.; Ding, S.; Cai, P.; Yuan, L.; Tian, Y.; Tu, W.; Hu, Q.-N. AdditiveChem: A comprehensive bioinformatics knowledge-base for food additive chemicals. Food Chem. 2020, 308, 125519. [CrossRef] [PubMed]

12. Ebrahimi, I.; Gashti, M.P. Extraction of polyphenolic dyes from henna, pomegranate rind, andPterocarya fraxinifoliafor nylon 6 dyeing. Color. Technol. 2016, 132, 162-176. [CrossRef]

13. Micó-Vicent, B.; Martínez-Verdú, F.; Novikov, A.; Stavitskaya, A.; Vinokurov, V.; Rozhina, E.; Fakhrullin, R.F.; Yendluri, R.; Lvov, Y. Stabilized Dye-Pigment Formulations with Platy and Tubular Nanoclays. Adv. Funct. Mater. 2018, 28, 1703553. [CrossRef]

14. Stafford, H.A. Anthocyanins and betalains: Evolution of the mutually exclusive pathways. Plant Sci. 1994, 101, 91-98. [CrossRef]

15. Azeredo, H.M. Betalains: Properties, sources, applications, and stability-A review. Int. J. Food Sci. Technol. 2009, 44, 2365-2376. [CrossRef]

16. Khan, M.I. Stabilization of betalains: A review. Food Chem. 2016, 197, 1280-1285. [CrossRef] 
17. TuTunchi, P.; Roufegarinejad, L.; Hamishehkar, H.; Alizadeh, A. Extraction of red beet extract with $\beta$-cyclodextrin-enhanced ultrasound assisted extraction: A strategy for enhancing the extraction efficacy of bioactive compounds and their stability in food models. Food Chem. 2019, 297, 124994. [CrossRef]

18. Escribano, J.; Cabanes, J.; Jiménez-Atiénzar, M.; Ibañez-Tremolada, M.; Gómez-Pando, L.R.; García-Carmona, F.; Gandía-Herrero, F. Characterization of betalains, saponins and antioxidant power in differently colored quinoa (Chenopodium quinoa) varieties. Food Chem. 2017, 234, 285-294. [CrossRef]

19. Dhananjayan, I.; Kathiroli, S.; Subramani, S.; Veerasamy, V. Ameliorating effect of betanin, a natural chromoalkaloid by modulating hepatic carbohydrate metabolic enzyme activities and glycogen content in streptozotocin-Nicotinamide induced experimental rats. Biomed. Pharmacother. 2017, 88, 1069-1079. [CrossRef]

20. Amjadi, S.; Ghorbani, M.; Hamishehkar, H.; Roufegarinejad, L. Improvement in the stability of betanin by liposomal nanocarriers: Its application in gummy candy as a food model. Food Chem. 2018, 256, 156-162. [CrossRef]

21. Zhang, J.; Hou, X.; Ahmad, H.; Zhang, H.; Zhang, L.; Wang, T. Assessment of free radicals scavenging activity of seven natural pigments and protective effects in AAPH-challenged chicken erythrocytes. Food Chem. 2014, 145, 57-65. [CrossRef] [PubMed]

22. Martins, N.; Roriz, C.L.; Morales, P.; Barros, L.; Ferreira, I.C. Coloring attributes of betalains: A key emphasis on stability and future applications. Food Funct. 2017, 8, 1357-1372. [CrossRef] [PubMed]

23. von Elbe, J.H.; Maing, I.-Y.; Amundson, C.H. Color stability of betanin. J. Food Sci. 1974, 39, $334-337$. [CrossRef]

24. Kearsley, M.W.; Katsaboxakis, K.Z. Stability and use of natural colours in foods Red beet powder, copper chlorophyll powder and cochineal. Int. J. Food Sci. Technol. 1980, 15, 501-514. [CrossRef]

25. Amjadi, S.; Nazari, M.; Alizadeh, S.A.; Hamishehkar, H. Multifunctional betanin nanoliposomes-incorporated gelatin/chitosan nanofiber/ZnO nanoparticles nanocomposite film for fresh beef preservation. Meat Sci. 2020, 167, 108161. [CrossRef]

26. Boyles, C.; Sobeck, S.J.S. Photostability of organic red food dyes. Food Chem. 2020, 315, 126249. [CrossRef]

27. Amjadi, S.; Abbasi, M.M.; Shokouhi, B.; Ghorbani, M.; Hamishehkar, H. Enhancement of therapeutic efficacy of betanin for diabetes treatment by liposomal nanocarriers. J. Funct. Foods 2019, 59, 119-128. [CrossRef]

28. Rostamabadi, H.; Falsafi, S.R.; Jafari, S.M. Nanoencapsulation of carotenoids within lipid-based nanocarriers. J. Control. Release 2019, 298, 38-67. [CrossRef]

29. Theng, B.K.G. Clay-Polymer Interactions: Summary and Perspectives. Clays Clay Miner. 1982, 30, 1-10. [CrossRef]

30. Ghadiri, M.; Chrzanowski, W.; Rohanizadeh, R. Biomedical applications of cationic clay minerals. RSC Adv. 2015, 5, 29467-29481. [CrossRef]

31. Uddin, M.K. A review on the adsorption of heavy metals by clay minerals, with special focus on the past decade. Chem. Eng. J. 2017, 308, 438-462. [CrossRef]

32. Tian, L.; Xiong, L.; Chen, X.; Guo, H.; Zhang, H.; Chen, X. Enhanced Electrochemical Properties of Gel Polymer Electrolyte with Hybrid Copolymer of Organic Palygorskite and Methyl Methacrylate. Materials 2018, 11, 1814. [CrossRef]

33. Mu, B.; Wang, A. Adsorption of dyes onto palygorskite and its composites: A review. J. Environ. Chem. Eng. 2016, 4, 1274-1294. [CrossRef]

34. Lu, Y.; Dong, W.; Wang, A.; Ding, J.; Wang, Q.; Hui, A.; Wang, A. Optimal Synthesis of Environment-Friendly Iron Red Pigment from Natural Nanostructured Clay Minerals. Nanomaterials 2018, 8, 925. [CrossRef] [PubMed]

35. Li, S.; Mu, B.; Wang, X.; Kang, Y.; Wang, A. A Comparative Study on Color Stability of Anthocyanin Hybrid Pigments Derived from 1D and 2D Clay Minerals. Materials 2019, 12, 3287. [CrossRef]

36. Drits, V.A.; Sokolova, G.V. Structure of palygorskite. Am. Inst. Phys. 1971, 16, 183-185.

37. Galan, E. Properties and applications of palygorskite-sepiolite clays. Clay Miner. 1996, 31, 443-453. [CrossRef]

38. Tian, G.; Wang, W.; Wang, D.; Wang, Q.; Wang, A. Novel environment friendly inorganic red pigments based on attapulgite. Powder Technol. 2017, 315, 60-67. [CrossRef]

39. Li, S.; Ding, J.; Mu, B.; Wang, X.; Kang, Y.; Wang, A. Acid/base reversible allochroic anthocyanin/palygorskite hybrid pigments: Preparation, stability and potential applications. Dye. Pigment. 2019, 171, 107738. [CrossRef] 
40. Fu, Y.; Wang, W.; Zhang, L.; Vinokurov, V.; Stavitskaya, A.V.; Lvov, Y. Development of Marine Antifouling Epoxy Coating Enhanced with Clay Nanotubes. Materials 2019, 12, 4195. [CrossRef]

41. Churchman, G.J.; Davy, T.J.; Aylmore, L.A.G.; Gilkes, R.; Self, P.G. Characteristics of fine pores in some halloysites. Clay Miner. 1995, 30, 89-98. [CrossRef]

42. Zhang, Y.; Tang, A.; Yang, H.; Ouyang, J. Applications and interfaces of halloysite nanocomposites. Appl. Clay Sci. 2016, 119, 8-17. [CrossRef]

43. Tonelli, M.; Baglioni, P.; Ridi, F. Halloysite Nanotubes as Nano-Carriers of Corrosion Inhibitors in Cement Formulations. Materials 2020, 13, 3150. [CrossRef]

44. Ramadass, K.; Singh, G.; Lakhi, K.S.; Benzigar, M.R.; Yang, J.-H.; Kim, S.; Almajid, A.M.; Belperio, T.; Vinu, A. Halloysite nanotubes: Novel and eco-friendly adsorbents for high-pressure CO2 capture. Microporous Mesoporous Mater. 2019, 277, 229-236. [CrossRef]

45. Gaaz, T.S.; Sulong, A.B.; Kadhum, A.A.H.; Nassir, M.H.; Al-Amiery, A.A. Impact of Sulfuric Acid Treatment of Halloysite on Physico-Chemic Property Modification. Materials 2016, 9, 620. [CrossRef] [PubMed]

46. Zheng, P.; Du, Y.; Ma, X. Selective fabrication of iron oxide particles in halloysite lumen. Mater. Chem. Phys. 2015, 151, 14-17. [CrossRef]

47. Lvov, Y.; Shchukin, D.G.; Möhwald, H.; Price, R.R. Halloysite Clay Nanotubes for Controlled Release of Protective Agents. ACS Nano 2008, 2, 814-820. [CrossRef]

48. Zhang, Y.; Wang, W.; Mu, B.; Wang, Q.; Wang, A. Effect of grinding time on fabricating a stable methylene blue/palygorskite hybrid nanocomposite. Powder Technol. 2015, 280, 173-179. [CrossRef]

49. Lvov, Y.; Wang, W.; Zhang, L.; Fakhrullin, R. Halloysite Clay Nanotubes for Loading and Sustained Release of Functional Compounds. Adv. Mater. 2015, 28, 1227-1250. [CrossRef]

50. Santos, A.C.; Ferreira, C.; Veiga, F.; Ribeiro, A.J.; Panchal, A.; Lvov, Y.; Agarwal, A. Halloysite clay nanotubes for life sciences applications: From drug encapsulation to bioscaffold. Adv. Colloid Interface Sci. 2018, 257, 58-70. [CrossRef]

51. Tang, J.; Zong, L.; Mu, B.; Kang, Y.; Wang, A. Attapulgite/carbon composites as a recyclable adsorbent for antibiotics removal. Korean J. Chem. Eng. 2018, 35, 1650-1661. [CrossRef]

52. Dong, W.; Lu, Y.; Wang, A.; Zong, L.; Zhu, Y.; Kang, Y.; Wang, A. A new route to fabricate high-efficient porous silicate adsorbents by simultaneous inorganic-organic functionalization of low-grade palygorskite clay for removal of Congo red. Microporous Mesoporous Mater. 2019, 277, 267-276. [CrossRef]

53. Marchuk, M.; Selig, M.J.; Celli, G.B.; Lawrence, P.; Smilgies, D.-M.; Abbaspourrad, A. Mechanistic investigation via QCM-D into the color stability imparted to betacyanins by the presence of food grade anionic polysaccharides. Food Hydrocoll. 2019, 93, 226-234. [CrossRef]

54. Zhuang, G.; Jaber, M.; Rodrigues, F.; Rigaud, B.; Walter, P.; Zhang, Z. A new durable pigment with hydrophobic surface based on natural nanotubes and indigo: Interactions and stability. J. Colloid Interface Sci. 2019, 552, 204-217. [CrossRef]

55. Wang, X.; Mu, B.; Hui, A.; Wang, Q.; Wang, A. Low-cost bismuth yellow hybrid pigments derived from attapulgite. Dye. Pigment. 2018, 149, 521-530. [CrossRef]

56. Cheng, H.; Frost, R.L.; Yang, J.; Liu, Q.; He, J. Infrared and infrared emission spectroscopic study of typical Chinese kaolinite and halloysite. Spectrochim. Acta Part A Mol. Biomol. Spectrosc. 2010, 77, 1014-1020. [CrossRef] [PubMed]

57. Zhang, A.; Mu, B.; Luo, Z.; Wang, A. Bright blue halloysite/CoAl 2 O 4 hybrid pigments: Preparation, characterization and application in water-based painting. Dye. Pigment. 2017, 139, 473-481. [CrossRef]

58. Wu, S.; Cui, H.; Wang, C.; Hao, F.; Liu, P.; Xiong, W. In situ self-assembled preparation of the hybrid nanopigment from raw sepiolite with excellent stability and optical performance. Appl. Clay Sci. 2018, 163, 1-9. [CrossRef]

59. Yan, W.; Yuan, P.; Chen, M.; Wang, L.; Liu, D. Infrared spectroscopic evidence of a direct addition reaction between palygorskite and pyromellitic dianhydride. Appl. Surf. Sci. 2013, 265, 585-590. [CrossRef]

60. Carazo, E.; Borrego-Sánchez, A.; García-Villén, F.; Sánchez-Espejo, R.; Iborra, C.V.; Cerezo, P.; Aguzzi, C. Adsorption and characterization of palygorskite-isoniazid nanohybrids. Appl. Clay Sci. 2018, 160, 180-185. [CrossRef]

61. Frost, R.L.; Xi, Y.; He, H. Synthesis, characterization of palygorskite supported zero-valent iron and its application for methylene blue adsorption. J. Colloid Interface Sci. 2010, 341, 153-161. [CrossRef] 
62. Zhang, Y.; Zhang, J.; Wang, A. Facile preparation of stable palygorskite/methyl violet@SiO2 "Maya Violet" pigment. J. Colloid Interface Sci. 2015, 457, 254-263. [CrossRef]

63. Desai, N.D.; Khot, K.V.; Dongale, T.; Musselman, K.P.; Bhosale, P.N. Development of dye sensitized TiO2 thin films for efficient energy harvesting. J. Alloys Compd. 2019, 790, 1001-1013. [CrossRef]

64. Aztatzi-Rugerio, L.; Granados-Balbuena, S.Y.; Zainos-Cuapio, Y.; Ocaranza-Sánchez, E.; Rojas-López, M. Analysis of the degradation of betanin obtained from beetroot using Fourier transform infrared spectroscopy. J. Food Sci. Technol. 2019, 56, 3677-3686. [CrossRef] [PubMed]

65. Kumar, S.N.A.; Ritesh, S.K.; Sharmila, G.; Muthukumaran, C. Extraction optimization and characterization of water soluble red purple pigment from floral bracts of Bougainvillea glabra. Arab. J. Chem. 2017, 10, S2145-S2150. [CrossRef]

66. Wang, W.; Tian, G.; Zhang, Z.; Wang, A. From naturally low-grade palygorskite to hybrid silicate adsorbent for efficient capture of Cu(II) ions. Appl. Clay Sci. 2016, 132, 438-448. [CrossRef]

67. Tsoufis, T.; Katsaros, F.; Kooi, B.J.; Bletsa, E.; Papageorgiou, S.; Deligiannakis, Y.; Panagiotopoulos, I. Halloysite nanotube-magnetic iron oxide nanoparticle hybrids for the rapid catalytic decomposition of pentachlorophenol. Chem. Eng. J. 2017, 313, 466-474. [CrossRef]

68. Fidecka, K.; Giacoboni, J.; Picconi, P.; Vago, R.; Licandro, E. Quantification of amino groups on halloysite surfaces using the Fmoc-method. RSC Adv. 2020, 10, 13944-13948. [CrossRef]

69. Zhang, Y.; Li, Y.; Zhang, Y. Preparation and intercalation structure model of halloysite-stearic acid intercalation compound. Appl. Clay Sci. 2020, 187, 105451. [CrossRef]

Publisher's Note: MDPI stays neutral with regard to jurisdictional claims in published maps and institutional affiliations.

(C) 2020 by the authors. Licensee MDPI, Basel, Switzerland. This article is an open access article distributed under the terms and conditions of the Creative Commons Attribution (CC BY) license (http://creativecommons.org/licenses/by/4.0/). 